should take particular care to see that security issues are not raised or discussed in a manner calculated to raise doubts as to British good faith or efficiency in so vital a matter. Further, by the consistent exposition of the positive conception of security to which the National Science Foundation gave admirable expression in its last annual report, they could contribute also to the formation of a climate of opinion calculated both to encourage the smooth operation of the unofficial checks and balances which are usually more effective than official action, and the vision, sense and vigilance which are the ultimate safeguard. It might well be worth while exploring Dr. Conant's suggestion of a Joint Anglo-American Commission to examine the security issue, if indeed that could not be better don $\theta$ by the academic alliance he also suggested.

\section{ANNUAL REVIEW OF BIOCHEMISTRY-A PERENNIAL PROBLEM}

\section{Annual Review of Biochemistry}

Edited by J. Murray Luck, in association with Frank W. Allen and Gordon Mackinney. Pp. $x+768$. (Palo Alto, Calif.: Annual Reviews, Inc., 1957.) 7 dollars.

THE twenty-sixth volume of the "Annual Review of Biochemistry" shows several changes. The number of chapters is reduced from twenty-three to twenty, the sections on lipid chemistry, cancer, immunochemistry, viruses, cellular particles, drugs and fungi being omitted and replaced by sections on X-ray studies of compounds of biological interest, biochemistry in the U.S.S.R., biochemistry of muscle, and clinical applications of biochemistry. In part, these changes reflect the established practice of not reviewing annually certain aspects of biochemistry. However, in this issue, the editors have announced their intention of transferring to sister volumes topics which seem more appropriate to microbiology or to plant or animal physiology. It is to be hoped that this does not mean that certain topics of interest to biochemists are to be permanently removed from this book. One pleasing feature of the "Annual Review of Biochemistry" is that it is a book for biochemists to browse in, in addition to providing an annual refresher course; it is to be hoped that this feature can be retained.

In so far as individual chapters are concerned, the editors claim to insist that reviews shall be critical appraisals and not summaries. Nevertheless, it is clear from reading this book that the style of the individual chapter is more often dictated by the state of the subject than by editorial policy. Thus, Steinberg and Mihalyi in their chapter on the chemistry of proteins have, in the space of thirty-four pages, welded together 340 references into an unusually lucid, critical and well-balanced review. The chapter is, in a sense, a tribute to those who have contributed to methods of determining protein structure, since a new approach to the vexed problem of protein purity, by considering proteins of known chemical structure, is now possible, and sections on genetic determination of protein structure, and relation of structure to function have an atmosphere of reality not previously possible. Dorfman, on the other hand, in a chapter on the biochemistry of steroid hormones has been content, for the most part, to list the many steroids formed by animals and their tissues without indicating how they are formed. Indeed, one gets the impression from this chapter that with steroids the end rather than the means to the end is the important consideration, and a thorough briefing in steroid biochemistry would appear to be an essential prerequisite in attempting to read this section.

Many authors have complained in their prefatory remarks of the vast extent of literature to be reviewed. One effect of this seems to be that critical considerations have to be so brief that they perhaps lose their value. This type of difficulty was evident in the section on carbohydrate metabolism by de Duve and Hers. This would perhaps suggest that the summary may, after all, be the best way of dealing with much of the new knowledge in those topics reviewed annually. In cases where a notable change in the subject has occurred during the year, more space could then be devoted to a comprehensive and critical account. In this connexion, in the present volume, the revision of $\Delta F^{0}$ for hydrolysis of the pyrophosphate bond in adenosine triphosphate from 12 down to $7 \mathrm{kcal} / \mathrm{mole}$ is considered only briefly by Mahler and by Weber. One would have thought that a re-evaluation of this magnitude of one of the most important thermodynamic considerations in bioohemistry would have received more than passing mention. It would be interesting to know, for example, why previous estimates have been so much in error, and how thermodynamic balance sheets such as that for the triosephosphate dehydrogenase reaction have passed the auditors in the past.

In the case of those topics which do not merit annual review, the present policy of publishing a critical type of review from time to time would seem to be admirable. In this volume, the chapters by Kendrew and Perutz on X-ray studies of compounds of biological interest and by Rimington on hæm pigments and porphyrins are excellent illustrations of what can be achieved in this connexion.

The chapter by Jakob A. Stekol on biochemistry in the U.S.S.R. seems to raise a further problem in relation to future policy. An attempt is made here to review the whole of research in animal biochemistry by Soviet biochemists in recent years. The author must be congratulated for attempting this impossible task. It was difficult not to conclude after reading this chapter that many of the papers must have suffered in translation, for several of the abstracted comments are scarcely intelligible. This was particularly true of the somewhat ideological discussion on the last page. It is to be hoped that in future volumes of the "Annual Review of Biochemistry" it will be unnecessary to review Russian biochemistry in a separate chapter, but that it will be possible to record the contributions of Soviet biochemists in the ordinary chapters of this book.

The prefatory chapter this year is by Sir Rudolph Peters and is entitled "Forty-five Years of Biochemistry". Written in a most persuasive and charming manner, it not only records Sir Rudolph Peters's recollections of personalities and landmarks in the history of the subject, but also his conclusions as to the future of the subject and the training of biochemists. The editors are to be especially congratulated on their choice of author for this particular chapter this year. PhILIP J. RANDLE 